\title{
ORIGINAL ARTICLE \\ Patients with traumatic spinal cord injuries and their satisfaction with their general practitioner
}

\author{
EM Hagen ${ }^{1,2}$, KE Grimstad $^{3}$, L Bovim $^{3}$ and M Gronning ${ }^{1,2}$
}

Objective: The objective of this study was to examine how satisfied patients with traumatic spinal cord injury (TSCI) are with their general practitioners (GP).

Materials and methods: The study included patients with TSCI, injured in the period 1982-2001 and living in western Norway. We performed a structured telephonic interview of the patients in the period 2004-2007. A total of 105 (59.3\%) patients participated. Results: Patients with TSCI were in general satisfied with their GP. Older patients were most satisfied, and patients with incomplete thoracic SCI were least satisfied. Patients with anxiety and/or depression reported low satisfaction with their GP on several parameters. Conclusions: Patients with incomplete SCI were least satisfied probably because their physicians do not acknowledge their complicated medical complaints and do not meet the patient's expectations. Patients with anxiety and/or depression were more likely to report low satisfaction with their GP.

Spinal Cord (2012) 50,527-532; doi:10.1038/sc.2011.187; published online 17 January 2012

Keywords: traumatic spinal cord injury; patient's satisfaction; general practitioners; primary health care

\section{INTRODUCTION}

To improve the quality of general practitioner (GP) services, the list patient system reform for GPs was introduced in Norway in June $2001 .^{1}$ Since then each inhabitant is listed with a general practitioner. The patients have the opportunity to change their GP, but in small communities, this might be difficult. The list patient system shall ensure equity in the use of health care services for the entire population. According to international experience this system will increase the perceived quality of the patient physician relationship. ${ }^{2}$ Following the introduction of the list patient system reform, studies in Norway have shown that people in general are more satisfied than they were earlier. ${ }^{3}$

Patients with chronic illness usually have more frequent contact with the GP than patients without chronic illness; on average 3.5 visits versus 2.5 visits per year. ${ }^{4}$ Patients with traumatic spinal cord injury (TSCI) need frequent contact with their physician as SCI often lead to multiple medical complications. The patients need extensive practical arrangements both at home and at work, of which medical certificates from the GP are needed. We wanted to examine the TSCI patient's satisfaction with their GP.

\section{MATERIALS AND METHODS}

Study population

The study included patients from western Norway who had a TSCI in the period 1982-2001. ${ }^{5}$ Patients with non-traumatic spinal cord injuries were not included. TSCI was defined according to Kraus et al. ${ }^{6}$ as an acute, traumatic lesion of the spinal cord with varying degrees of motor and/or sensory deficit or paralysis. Although injuries of cauda equina were included, the definition excluded isolated injuries of other nerve roots. ${ }^{7}$

A total of 231 persons who were inhabitants of the Western Health Region during the period 1982-2001, sustained a TSCI; 182 men (78.8\%) and 49 women $(21.2 \%) .{ }^{8}$ At the start of the study 54 patients had died, 7 patients lived outside western Norway, and 56 patients did not respond. Eight men and one woman did not answer the specific questions regarding GP, and were excluded from this part of the project. A total of 105 (59.3\%) participated in this part of the study.

\section{Telephone enquiry}

A questionnaire was developed based on a literature review focusing on spasticity, pain, quality of life and patient satisfaction. A letter was sent to all patients injured in the period 1982-2001 inviting them to participate in this study. The patients agreed to participate in advance of the telephonic interview, which took place in the period 2004-2007 using the questionnaire.

The interviews were performed by two medical students and one occupational therapy student. The students were working part time as assisting nurses at the Spinal Cord Unit, Haukeland University Hospital, and they were all familiar with TSCI. The interviewer for each patient was chosen randomly. However, if this interviewer knew the patient well, another interviewer was chosen. The study was carried out independently of the Spinal Cord Unit and all patients were informed that the participation in this study had no impact on the patient care. The interviewers were trained before the study and they also had written explanations to the questionnaire to ensure consistency between the interviewers.

\section{The questionnaire}

The questionnaire elicited questions regarding pain, spasticity, quality of life and patient satisfaction. To assess satisfaction with their GP, the patients were asked to rank six questions as not true/correct, occasionally true/correct, mostly true/correct, or true/correct.

(1) Availability: It is easy to get in contact with my GP whenever I need.

(2) Understandable: My GP expresses themselves in a way that I can understand.

(3) Easy to ask: It is easy to ask my GP whenever I have a question.

(4) Understanding: I feel that my GP understands my situation.

${ }^{1}$ Department of Neurology, Haukeland University Hospital, Bergen, Norway; ${ }^{2}$ Department of Clinical Medicine, University of Bergen, Bergen, Norway and ${ }^{3}$ Faculty of Medicine and Dentistry, University of Bergen, Bergen, Norway

Correspondence: Dr EM Hagen, Department of Neurology, Haukeland University Hospital, Jonas Lies vei 65, Bergen N-5021, Norway.

E-mail: ellen.merete.hagen@helse-bergen.no

Received 17 July 2011; revised 5 December 2011; accepted 16 December 2011; published online 17 January 2012 
(5) Knowledge: I feel that my GP has knowledge of my condition.

(6) Overall satisfaction: I am satisfied with my GP.

Five of the participants failed to respond to one of the six questions.

\section{Demographic and clinical data}

Gender, age at injury $(0-30,31-60,60+$ years $)$, time since injury $(1-5,6-10$, 11-15, 16-20, 21-25 years), level of injury; cervical or thoracic-lumbar-sacral (TLS) and completeness of injury; complete or incomplete were recorded from the medical records (Table 1).

Spasticity, pain and chronic pain as reported by the patients were recorded as either yes, no or unknown. We measured anxiety and depression using Hospital Anxiety and Depression Scale (HADS), giving the results of yes, possible or no. The population size of the municipality where the patients were living at the time of interview was recorded (Table 1).

\section{Norwegian population data}

Norwegian Gallup standard municipal survey 2003 was used to compare satisfaction among patients with TSCI with the satisfaction reported by the Norwegian population. ${ }^{9}$ We adapted the questions used in the Norwegian Gallup standard municipal survey 2003 to be comparable to our questionnaire.

\section{Statistical analysis}

For categorical variables crude data and percentages are reported. Means and s.d.'s are reported for continuous variables. To compare groups, the Pearson's $\chi^{2}$ test ${ }^{10}$ was used for nominal variables, and analysis of variance for continuous variables adhering to the normal distribution.

To compare results from our study with data from the Norwegian Gallup study, we calculated a mean percentage score for each group (Figure 1).

The level of statistical significance was set at $0.05 .{ }^{1}$ All $P$-values are twotailed. Statistical analyses were conducted with PASW 18 (SPSS, Chicago, IL, USA) and StatXact 9 (Cytel Software, Cambridge, MA, USA) Cytel Studio.

\section{Approvals}

The study was approved by the Regional Committee for Medical Research Ethics and the Norwegian Data Inspectorate.

\section{RESULTS}

Gender, age and level of injury

Eighty four men and 21 women were interviewed (Table 1). Mean age at injury was 37.6 years (8.3-81.5 years), 35.2 years for females and 38.2 years for men. The mean time from injury to the interview was 11.9 years (4.0-25.2 years), 12.0 years for women and 11.9 years for men. There was no statistically significant difference between the group of patients who were interviewed and the patients who were not interviewed with regard to gender, age at injury and completeness of injury. The response rate was however higher among patients with lower injuries (TLS; 76\%), than among patients with cervical injuries (57\%).

Table 2 displays the patients' satisfaction with medical services in relation to gender and level and completeness of injury, percentages given. Women scored higher on all six questions compared to men, this was however not significant. The only significant difference was found in the overall satisfaction with their GP in relation to level and completeness of injury.

We explored the patients satisfaction with medical services in relation to age at the time of interview (in groups) and in relation to time since injury (in groups). The oldest group (67+ years) reported the greatest degree of satisfaction, whereas patients aged 35-49 years, scored lowest. There was, however, no statistical significance between the groups either for age at interview or for time since injury.

In Norway most GPs are self-employed with contracts administrated by the municipalities. ${ }^{11}$ There was no statistical significance between the groups with regard to population size.
Table 1 Demographic and injury characteristics of 105 patients with traumatic spinal cord injury

\begin{tabular}{|c|c|}
\hline Characteristics & $\mathrm{N}=105(\%)$ \\
\hline Age at injury (years), mean (s.d.) & $37.6(17.2)$ \\
\hline Time since injury (years), mean (s.d.) & $11.9(6.0)$ \\
\hline \multicolumn{2}{|l|}{ Age at interview (years), mean (s.d.) } \\
\hline Total & $49.5(16.5)$ \\
\hline Male & $50.1(16.7)$ \\
\hline Female & $47.2(15.5)$ \\
\hline \multicolumn{2}{|c|}{ Age according to level and completeness of injury (years), mean (s.d.) } \\
\hline Cervical complete & $47.1(12.6)$ \\
\hline Cervical incomplete & $44.3(15.4)$ \\
\hline TLS complete & $61.0(15.8)$ \\
\hline TLS incomplete & $40.7(14.0)$ \\
\hline \multicolumn{2}{|l|}{ Gender, n (\%) } \\
\hline Male & $84(80.0)$ \\
\hline Female & $21(20.0)$ \\
\hline \multicolumn{2}{|l|}{ Age groups at time of interview, $\mathrm{n}(\%)$} \\
\hline $14-30$ years & $14(13.3)$ \\
\hline $31-45$ years & $39(37.1)$ \\
\hline $46-60$ years & $23(21.9)$ \\
\hline $61-75$ years & $22(21.0)$ \\
\hline $76+$ years & $7(6.7)$ \\
\hline \multicolumn{2}{|l|}{ Level and completeness of injury, $\mathrm{n}(\%)$} \\
\hline Cervical complete & $26(24.8)$ \\
\hline Cervical incomplete & $36(34.3)$ \\
\hline TLS complete & $31(29.5)$ \\
\hline TLS incomplete & $12(11.4)$ \\
\hline \multicolumn{2}{|l|}{ Time since injury, $\mathrm{n}(\%)$} \\
\hline $1-5$ years & $18(17.1)$ \\
\hline $6-10$ years & $38(36.2)$ \\
\hline $11-15$ years & $19(18.1)$ \\
\hline $16-20$ years & $20(19.0)$ \\
\hline $21-25$ years & $10(9.5)$ \\
\hline \multicolumn{2}{|l|}{ Spasticity, n (\%) } \\
\hline Yes & $77(73.3)$ \\
\hline No & $24(22.9)$ \\
\hline Unknown & $4(3.8)$ \\
\hline \multicolumn{2}{|l|}{ Pain, n (\%) } \\
\hline Yes & $74(70.5)$ \\
\hline No & $27(25.7)$ \\
\hline Unknown & $4(3.8)$ \\
\hline \multicolumn{2}{|l|}{ Chronic pain, n (\%) } \\
\hline Yes & $54(51.4)$ \\
\hline No & $46(43.8)$ \\
\hline Unknown & $5(4.8)$ \\
\hline \multicolumn{2}{|l|}{ Anxiety n (\%) } \\
\hline Yes & $8(7.6)$ \\
\hline Possible & $7(6.7)$ \\
\hline No & $90(85.7)$ \\
\hline \multicolumn{2}{|l|}{ Depression, n (\%) } \\
\hline Yes & $5(4.8)$ \\
\hline Possible & $11(10.5)$ \\
\hline No & $89(84.8)$ \\
\hline \multicolumn{2}{|l|}{ Municipality population, n (\%) } \\
\hline$<3000$ & $11(5.6)$ \\
\hline 3000-7999 & $26(13.3)$ \\
\hline 8000-19999 & $16(8.2)$ \\
\hline $20000-89999$ & $16(8.2)$ \\
\hline$\geqslant 90000$ & $36(18.5)$ \\
\hline
\end{tabular}

Abbreviation: TLS, thoracic-lumbar-sacral. 


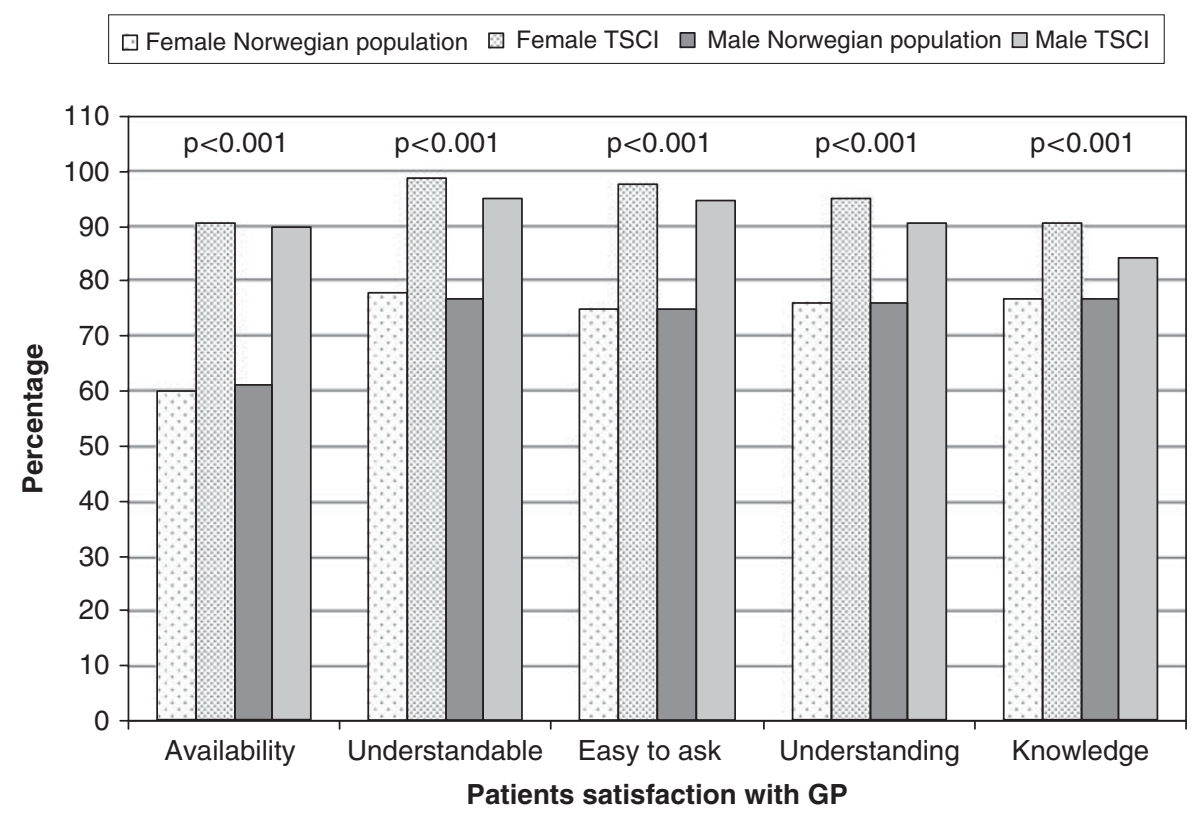

Figure 1 Patients satisfaction with their general practitioners among patients with traumatic spinal cord injuries and the Norwegian population.

Many patients with TSCI have spasticity, pain, chronic pain, anxiety and depression, which may influence their contact with their GP. Table 3 shows the patients satisfaction with medical services in relation to spasticity, pain, anxiety and depression. Patients with anxiety according to HADS reported less understandable GP compared with those without or with possible anxiety $(P=0.040)$. Patients with depression according to HADS reported their GP to be less understandable $(P=0.036)$, not so easy to ask $(P=0.010)$ and less understanding $(P=0.017)$ compared with the patients without or with possible depression.

Figure 1 shows the patient's satisfaction with GP among males and females with TSCI and the Norwegian population, by calculating a mean percentage score for each group. There were statistical difference both for males and females compared with the Norwegian population $(P<0.001)$.

\section{DISCUSSION}

The patients in our study were in general satisfied with their GP. This is consistent with previous national and international publications, which have shown that assessments of primary health care in general are high. ${ }^{9,12}$ Measuring the patients' subjective views on satisfaction can be a challenge, as personality traits and personality type may have an impact on the answers, rather than the objective factors in the actual situation. ${ }^{13}$ The high rates of satisfaction may partly be explained by the patient's relative dependence on and need to keep a positive relationship with their GP. ${ }^{14}$

The physicians were given the lowest scores on the question regarding knowledge, which may be related to the physicians limited knowledge about spinal cord injuries. ${ }^{15}$ Most GPs have a low number of patients with this injury, and therefore their knowledge and experience of SCI are low. ${ }^{16}$

According to international literature the physicians' knowledge of chronic disability/disease is a problem. ${ }^{17,18}$ Patients feel they have to spend much effort in teaching their physician about his or her disability. ${ }^{15}$ They also feel that the physician often focus on the disability per se rather than other specific problems they have. ${ }^{16}$
In our data, the patients aged $67+$ years seemed to be more satisfied than patients in the other age groups. The elderly patients use their GP more frequently than younger and therefore become more familiar with their GP. ${ }^{19}$ Campbell et al. ${ }^{20}$ found a clear correlation between age and satisfaction with primary health care. In their study, older patients scored higher in all areas examined. The differences between older and younger patients were particularly evident regarding questions about the physicians' knowledge of the patient, the physician's role in the coordination of care, overall satisfaction and the assessment of interpersonal aspects. ${ }^{20}$

Persons aged 35-49 years seemed to be least satisfied with their GP. This differs from other studies where the percentage of satisfaction increases with age from 25 years. ${ }^{9}$ Presently the documentation is limited, but our clinical experience is that the expectations regarding health care often is very high among persons in this age group. Older patients have fewer expectations.

The Norwegian HUNT 3 found that women and elderly patients scored higher on questions regarding experience of the physician and of physician-patient relationship. ${ }^{19}$ Women visit their GP more frequently than men and this may have an effect on how they perceive their GP, similarly to elderly patients. ${ }^{19}$ Therefore we expected women with TSCI to be more satisfied with their GP compared with men with TSCI. There was a trend, but not a statistically significant difference, probably due to small numbers.

The patients with incomplete injuries, both cervical and TLS scored low regarding satisfaction with their GP (Table 2). Patients with incomplete thoracic TLS injuries are on average younger than those with complete TLS injury and are often expected to have a higher level of function compared with patients with complete injury. The low percentage of satisfaction among patient with incomplete TLS may be due to the discrepancy between the GP's evaluation and how the patients perceive themselves. They may experience significant problems in the daily life but as they are not paralyzed, the GP may underestimate their problems.

We have previously found that patients with incomplete TLS have a higher risk of dying from suicide and accidental poisoning compared 
Table 2 Patients with traumatic spinal cord injuries: answers of patient's satisfaction according to gender and level and completeness of injury, percentages given

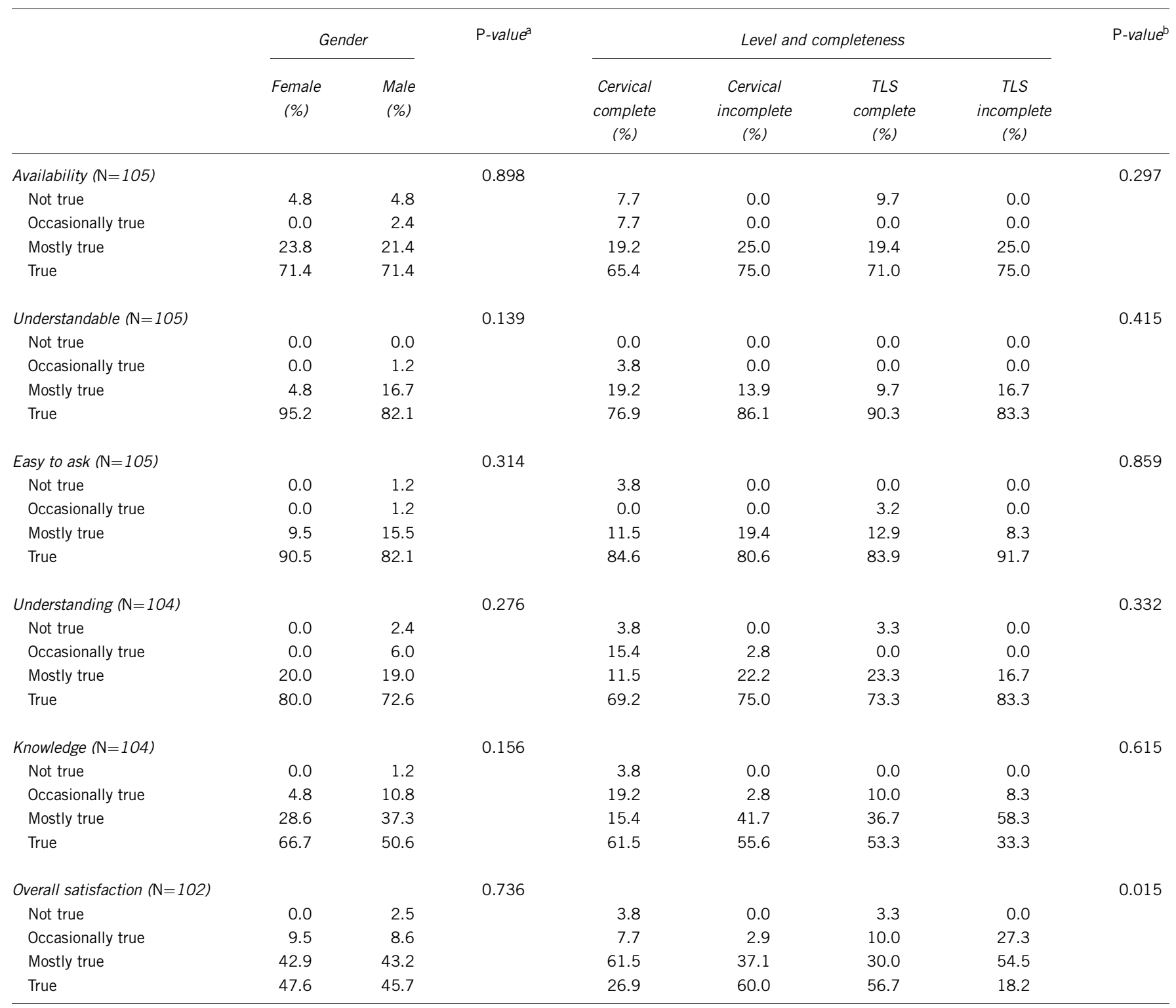

Abbreviation: TLS, thoracic-lumbar-sacral.

apearson's chi-square test.

bAnalysis of variance.

to other patients with TSCI. ${ }^{8}$ This may indicate that these patients suffer from a low quality of life post injury.

Patients with either anxiety or depression according to HADS reported their GP's to be less understandable, less easy to ask and less understanding (Table 3). There is an increased risk of depression after a TSCI. ${ }^{21,22}$ The Spinal Outreach Service has developed a Health Questionnaire, which can enable the GP to cover important clinical issues. $^{23}$ Depression is quite consistent over time in persons with TSCI, with the majority of change coming from those with clinically significant symptoms. ${ }^{21}$ Fann et al..$^{22}$ found a prevalence of probable major depression of $23 \%$, and a high lifetime prevalence of other psychiatric conditions, particularly anxiety disorders. ${ }^{22}$ They found a large gap in depression treatment in their population, which may indicate that the GP's underestimate these symptoms among TSCI patients. Examining anxiety and depression at multiple time points may help GP's to identify patients at risk.

Overall, patients with TSCI are more satisfied with their GP than the Norwegian population (Figure 1). This finding may be explained by the fact that the study was performed more than four years after the injury, in which time the patients have found their preferred GP.

\section{CONCLUSION}

Although patients with TSCI as a group were more satisfied with their GP than the Norwegian population, patients with incomplete SCI were least satisfied probably because their physicians do not acknowledge their complicated medical complaints and do not meet the patient's expectations. Patients with anxiety and/or depression were more likely to report low satisfaction with their GP. There is a need for 


\begin{tabular}{|c|c|c|c|c|c|c|c|}
\hline 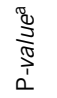 & & $\underset{\substack{0 \\
\infty \\
0 \\
0}}{0}$ & $\begin{array}{l}\stackrel{0}{0} \\
\stackrel{\infty}{0} \\
0\end{array}$ & $\begin{array}{l}\circ \\
\stackrel{1}{0} \\
0\end{array}$ & $\hat{0}$ & $\underset{\substack{\infty \\
m}}{0}$ & 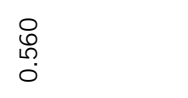 \\
\hline \multirow{3}{*}{ 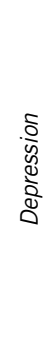 } & 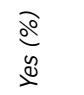 & O $\stackrel{\circ}{\circ} \stackrel{\circ}{\circ} \stackrel{\circ}{\dot{\infty}}$ & : $\stackrel{\circ}{\circ} \stackrel{\circ}{\stackrel{\sim}{~}}$ & 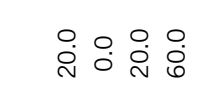 & 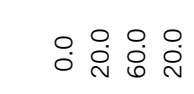 & 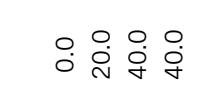 & 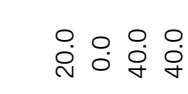 \\
\hline & 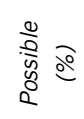 & O & O: & $\circ: \stackrel{m}{\stackrel{N}{N}}$ & 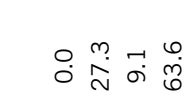 & 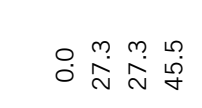 & 용 욤 \\
\hline & $\frac{\grave{2}}{\stackrel{2}{2}}$ & 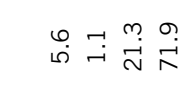 & 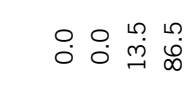 & 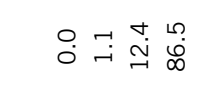 & 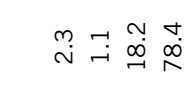 & 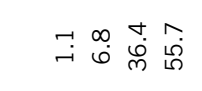 & 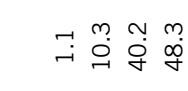 \\
\hline \multirow[t]{2}{*}{$\begin{array}{l}\stackrel{0}{3} \\
\stackrel{\pi}{\pi} \\
0^{\prime}\end{array}$} & & 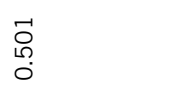 & $\begin{array}{l}\text { ơ } \\
\text { ơ } \\
0\end{array}$ & $\begin{array}{l}\hat{0} \\
\stackrel{0}{0}\end{array}$ & $\begin{array}{l}\stackrel{0}{1} \\
\stackrel{3}{0}\end{array}$ & $\underset{\substack{\infty \\
m \\
\infty \\
0}}{0}$ & $\begin{array}{l}m \\
\overrightarrow{0} \\
0 \\
0\end{array}$ \\
\hline & $\begin{array}{l}\frac{\partial 0}{0} \\
\frac{0}{20}\end{array}$ & 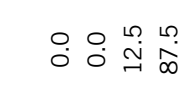 & ○: $\stackrel{\circ}{\stackrel{\sim}{\sim}} \stackrel{\circ}{\stackrel{\leftrightarrow}{N}}$ & 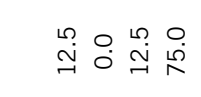 & ○ 욤 & 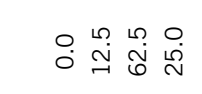 & 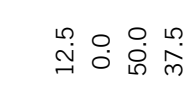 \\
\hline \multirow[t]{2}{*}{ : } & 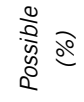 & 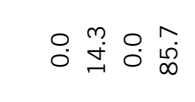 & 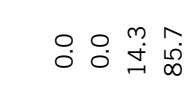 & $\stackrel{\circ}{\circ} \stackrel{\circ}{\circ} \stackrel{m}{\stackrel{\sim}{\rightarrow}} \underset{\infty}{\infty}$ & 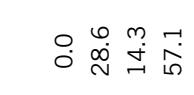 & 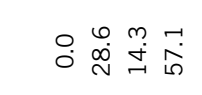 & 용 \\
\hline & $\begin{array}{l}\frac{\partial}{2} \\
\stackrel{2}{z}\end{array}$ & 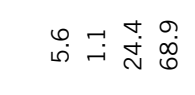 & 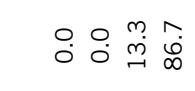 & ○ & 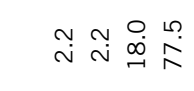 & 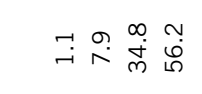 & 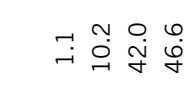 \\
\hline \multirow[t]{2}{*}{$\begin{array}{l}\stackrel{0}{\frac{\pi}{20}} \\
\frac{\pi}{10} \\
\frac{1}{1}\end{array}$} & & $\begin{array}{l}0 \\
\stackrel{0}{0} \\
0\end{array}$ & 包 & $\begin{array}{l}\mathscr{8} \\
\stackrel{\circ}{\circ} \\
0\end{array}$ & $\begin{array}{l}+ \\
\infty \\
\infty \\
0 \\
0\end{array}$ & $\begin{array}{l}\stackrel{0}{ } \\
\stackrel{5}{0} \\
0\end{array}$ & $\stackrel{\stackrel{\rho}{\leftrightarrow}}{\stackrel{\leftrightarrow}{\circ}}$ \\
\hline & 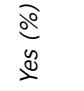 & 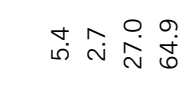 & 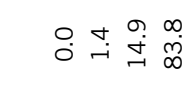 & 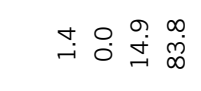 & 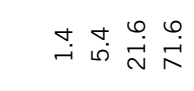 & ナ. & 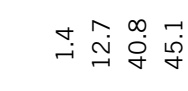 \\
\hline \multirow[t]{2}{*}{$\frac{\sqrt[5]{\pi}}{e^{2}}$} & $\frac{\partial 0}{2}$ & 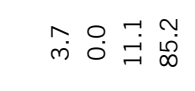 & 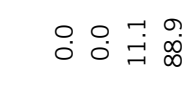 & 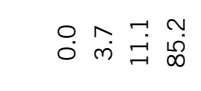 & 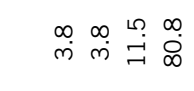 & ○ & 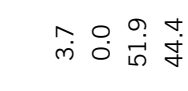 \\
\hline & 㐔 & 웅 : : $: \circ$ & 웅용요용 & 웅요 웅 & 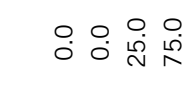 & 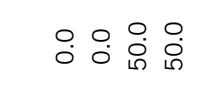 & 웅 잉 官 \\
\hline \multirow[t]{2}{*}{ 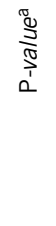 } & & $\begin{array}{l}\text { Oे } \\
\infty \\
\infty \\
0\end{array}$ & 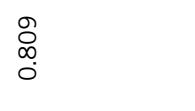 & $\begin{array}{l}\stackrel{m}{\sigma} \\
\stackrel{\circ}{\circ}\end{array}$ & $\underset{0}{\simeq}$ & 命 & $\begin{array}{l}\infty \\
\infty \\
\infty \\
0 \\
0\end{array}$ \\
\hline & 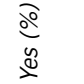 & 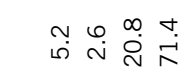 & 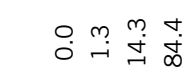 & 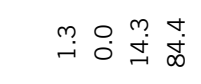 & $\stackrel{m}{\rightarrow} \underset{\sim}{m} \stackrel{\hat{\sigma}}{\sigma} \hat{r}$ & 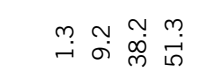 & 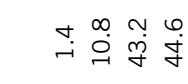 \\
\hline \multirow[t]{3}{*}{ 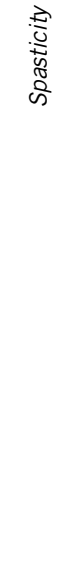 } & $\frac{\grave{\partial}}{2}$ & 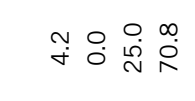 & 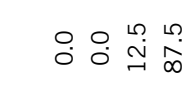 & 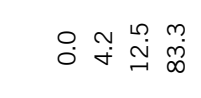 & 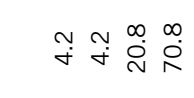 & $\circ \stackrel{n}{\circ} \underset{\sim}{\stackrel{N}{\sim}} \stackrel{m}{\sim} \underset{\infty}{\infty}$ & 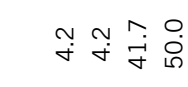 \\
\hline & 㐔 & 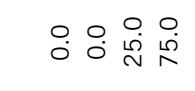 & 웅용요 옷 & O웅요용 & $\circ: \circ: \circ$ & 웅용요 옷 & 웅요 \\
\hline & & 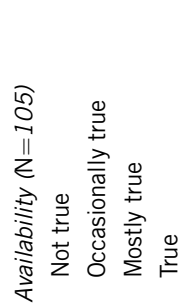 & 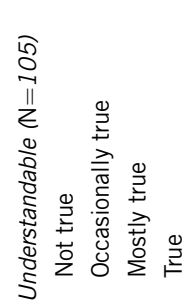 & 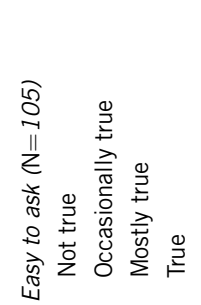 & 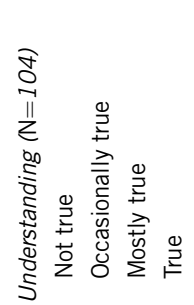 & 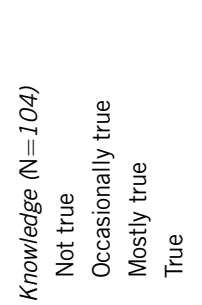 & 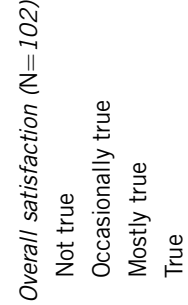 \\
\hline
\end{tabular}


greater awareness among GP's with regard to anxiety and depression among patient $s$ with TSCI.

\section{DATA ARCHIVING}

There were no data to deposit.

\section{CONFLICT OF INTEREST}

The authors declare no conflict of interest.

\section{ACKNOWLEDGEMENTS}

We thank all the patients who participated in this study, and Marianne Lundervik, Stian Halse and Aage Tornes, who performed the interviews. This study was supported by grants from the Western Norway Regional Health Authority.

1 Relating to amendments to Act 19 November 1982 No. 66 relating to health services in the municipalities and certain other laws (GP system), Ot. prp. nr. 99 (1998-1999). The Norwegian Ministry of Health and Care Services (1999).

2 Lian OS, Wilsgaard T. [Patient satisfaction with primary health care before and after the introduction of a list patient system]. Tidsskr Nor Laegeforen 2004; 124: 655-658.

3 Sandvik H, Hunskar S. [Telephone accessibility in general practices]. Tidsskr Nor Laegeforen 2005; 125: 182-185.

4 Finnvold JE, Svalund J, Paulsen B. After the Introduction of GP System-User Ratings of Physician Services. January. Report No. 01. Statistics Norway: Oslo, 2005.

5 Hagen EM, Eide GE, Rekand T, Gilhus NE, Gronning M. A 50-year follow-up of the incidence of traumatic spinal cord injuries in Western Norway. Spinal Cord 2010; 48: 313-318.

6 Kraus JF, Franti CE, Riggins RS, Richards D, Borhani NO. Incidence of traumatic spinal cord lesions. J Chronic Dis 1975; 28: 471-492.

7 Maynard FM, Bracken MB, Creasey G, Ditunno JF, Donovan WH, Ducker TB et al. International standards for neurological and functional classification of spinal cord injury. Spinal Cord 1997; 35: 266-274.
8 Hagen EM, Lie SA, Rekand T, Gilhus NE, Gronning M. Mortality after traumatic spinal cord injury: 50 years of follow-up. J Neurol Neurosurg Psychiatry 2010; 81: 368-373.

9 TNS Gallup. Norwegian Gallup Standard Municipal Survey 20032003.

10 Lydersen S, Fagerland MW, Laake P. Recommended tests for association in $2 \times 2$ tables. Stat Med 2009; 28: 1159-1175.

11 Grasdal AL, Monstad K. Inequity in the use of physician services before and after introducing patient lists in primary care. Int J Equity Health 2011; 10: 25.

12 Grol R, Wensing M. Patients evaluate general/family practice. The EUROPEP instrument. EQuiP, Wonca Region Europe, 2000.

13 Carlsen F, Bringedal B. [Population satisfaction with health care and physicians' job satisfaction]. Tidsskr Nor Laegeforen 2009; 129: 405-407.

14 Edwards C, Staniszweska S, Crichton N. Investigation of the ways in which patients' reports of their satisfaction with healthcare are constructed. Sociol Health IIIn 2004; 26: 159-183.

15 Welner S. A Provider's Guide for the Care of Women with Physical Disabilities \& Chronic Medical Conditions. The North Carolina Office on Disability and Health: Chapel Hill, NC, 1999.

16 Donnelly C, McColl MA, Charlifue S, Glass C, O'brien P, Savic G et al. Utilization, access and satisfaction with primary care among people with spinal cord injuries: a comparison of three countries. Spinal Cord 2007; 45: 25-36.

17 DeJong G. Primary care for persons with disabilities. An overview of the problem. Am J Phys Med Rehabil 1997; 76: S2-S8.

18 Burns TJ, Batavia Al, Smith QW, DeJong G. Primary health care needs of persons with physical disabilities: what are the research and service priorities? Arch Phys Med Rehabil 1990; 71: 138-143.

19 De Ridder K, Johnsen R, Holmen J. User evaluation of the GP system in Levanger and Verdal municipality. Analyses based on the HUNT 3. 2008.

20 Campbell JL, Ramsay J, Green J. Age, gender, socioeconomic, and ethnic differences in patients' assessments of primary health care. Qual Health Care 2001; 10: 90-95.

21 Saunders LL, Krause JS, Focht KL. A longitudinal study of depression in survivors of spinal cord injury. Spinal Cord 2012; 50: 72-77.

22 Fann JR, Bombardier CH, Richards JS, Tate DG, Wilson CS, Temkin N. Depression after spinal cord injury: comorbidities, mental health service use, and adequacy of treatment. Arch Phys Med Rehabil 2011; 92: 352-360.

23 Middleton J, Leong G, Cheok E, Mann L. Development of a checklist to support health monitoring and prevention activities of persons with $\mathrm{SCl}$ in general practice. Greater Metropolitan Clinical Taskforce, 21 December 2007. Available from: http://www. health.nsw.gov.au/resources/gmct/spinal/pdf/sos_hq.pdf. 